\title{
Modelagem na Educação Matemática para o desenvolvimento de conceitos de Análise Combinatória
}

\author{
Modelling in Mathematics Education for the development of Combinatorial \\ Analysis concepts
}

Ticiano Azevedo Bastos

Milton Rosa

\begin{abstract}
Resumo: Esse artigo tem como base uma pesquisa de mestrado que teve como objetivo identificar como a perspectiva sociocrítica da Modelagem Matemática poderia contribuir para 0 desenvolvimento de conceitos de Análise Combinatória. A pesquisa foi realizada com 17 alunos do $2^{\circ}$ ano do Ensino Médio de uma escola particular no vale do Rio Doce, na região leste do estado de Minas Gerais e com um professor de Educação Física. A abordagem metodológica utilizada nesse estudo foi qualitativa e os dados foram produzidos por meio de quatro blocos de atividades,
\end{abstract} dois questionários e uma entrevista semiestruturada, que foram conduzidos no período de setembro a novembro de 2018. Os resultados mostraram que as contribuições desse estudo estavam relacionadas com o desenvolvimento ativo da aprendizagem de conceitos combinatórios por meio de um olhar crítico sobre as práticas de treinamentos de musculação nas academias pesquisadas.

Palavras-chave: Modelagem Matemática. Perspectiva Sociocrítica. Análise Combinatória. Ensino Médio. Fichas de Treino em Academias.

Abstract: This article is based on a master's research that aimed to identify how the sociocritical perspective of Mathematical Modelling could contribute to the development of concepts of Combinatorial Analysis. The research was conducted with 17 sophomore High School students from a private school in the Vale do Rio Doce, in the eastern region of Minas Gerais and with a Physical Education teacher. The methodological approach used in this study was qualitative and the data

Ticiano Azevedo Bastos Mestre em Educação Matemática pela Universidade Federal de Ouro Preto (UFOP). Professor de Matemática no Colégio Nossa Senhora de Lourdes. Minas Gerais, Brasil. (iD) orcid.org/0000-0003-1259-5104 $\bowtie$ ticianogvmg@gmail.com Milton Rosa Doutorado em Educação (Liderança Educacional). Professor do Programa de PósGraduação em Educação Matemática pela Universidade Federal de Ouro Preto (UFOP). Minas Gerais, Brasil. iD orcid.org/0000-0002-5190-3862 $\triangle$ milton.rosa@ufop.edu.br Recebido em 21/01/2020 Aceito em 24/03/2020 Publicado em 10/04/2020 were produced through four activity blocks, two questionnaires, and one semistructured interview from september to november, 2018. The results showed that the contributions of this study were related to the active development of learning combinatorial concepts through a critical look over the practices of bodybuilding training in the researched gyms.

Keywords: Mathematical Modelling. Sociocritical perspective. Combinatorial Analysis. High School. Prescription Forms for Training Sheets.

\section{Introdução}

De modo geral, o ensino atual da Matemática tem gerado preocupações para a comunidade escolar, sociedade e pesquisadores da Educação Matemática. Contudo, o que se observa nas pesquisas é que a Matemática ensinada nas escolas e as práticas pedagógicas 
empregadas no ensino dessa disciplina não acompanharam a evolução social e tecnológica da sociedade pós-moderna (ROSA e OREY, 2012).

Diante desse contexto, dentre as tendências de ensino em Educação Matemática, a Modelagem Matemática pode auxiliar no atendimento das demandas impostas pela sociedade moderna com relação à resolução de situações-problema enfrentadas no cotidiano (ROSA e OREY, 2007). Assim, Rosa (2010) argumenta que, por meio da Modelagem Matemática, o processo de ensino e aprendizagem está desvinculado do sentido tradicional da prática docente que se direciona dos professores para alunos, pois a sua relevância tem como foco o resultado da relação dos alunos com o seu ambiente sociocultural.

Uma das prerrogativas dessa pesquisa foi identificar situações-problema que envolvessem conceitos de Análise Combinatória e que pudessem ser solucionados por meio da Modelagem Matemática para que os alunos melhor compreendessem esse conteúdo curricular. Nesse contexto, foi proposta uma prática de Modelagem Matemática em que os alunos deveriam analisar a construção das fichas de prescrições de treino ${ }^{1}$ nas academias para que percebessem como os conhecimentos de Análise Combinatória poderiam estar presentes no contexto da construção dessas fichas, bem como no funcionamento dos treinos nas academias.

Assim, partindo de um tema de interesse da maioria dos alunos, buscou-se compreender como ocorre a relação entre o número de diferentes prescrições de treino com os conhecimentos matemáticos de Análise Combinatória. Portanto, a utilização da Modelagem Matemática como um ambiente de aprendizagem ${ }^{2}$ procurou minimizar os impactos negativos na aprendizagem desse conteúdo.

De acordo com as observações do professor-pesquisador ${ }^{3}$, que é o primeiro autor desse

\footnotetext{
${ }^{1}$ As fichas de prescrições de treino ou fichas de treino são elaboradas com o objetivo de orientar os alunos de academia durante a realização de seu treino. Para a elaboração dessas é importante considerar algumas variáveis, como, por exemplo, intensidade, volume, frequência semanal e progressão dos exercícios (GENTIL, 2005). Na prática de Modelagem Matemática proposta nessa pesquisa, os alunos visitaram academias que escolheram, pois tinham como objetivo investigar se alguns conceitos de Análise Combinatória, como, por exemplo, permutações e combinações, estariam presentes na elaboração dessas fichas de treino.

20 ambiente é definido em termos de convite aos alunos de acordo com a argumentação elaborada por Skovsmose (2000). Nesse sentido, Barbosa (2001) argumenta que o envolvimento dos alunos ocorre na medida em que os seus interesses se encontram contemplados nas atividades propostas em sala de aula.

${ }^{3}$ O pesquisador é também professor da turma. A denominação professor-pesquisador é utilizada para se referir ao primeiro autor desse estudo que também é o professor da disciplina da turma pesquisada. É importante ressaltar que os professores-pesquisadores consideram a prática como um meio, um fundamento e uma destinação dos saberes que são suscitados em sala de aula e orientados pela sua ação reflexiva sobre o processo de ensino e aprendizagem que é desencadeado em sala de aula (MIRANDA, 2006).
} 
artigo, focalizando o seu olhar para a Educação Básica, principalmente, para o Ensino Médio, os questionamentos e as dúvidas que os alunos apresentaram em alguns conteúdos matemáticos, em especial, sobre a Análise Combinatória, instigou os autores a questionarem e refletirem sobre as práticas de ensino e aprendizagem desse conteúdo. Por exemplo, as anotações registradas no diário de campo do professor-pesquisador mostram que era recorrente a fala dos alunos quanto às dificuldades em compreender plenamente os conceitos e as aplicações da Análise Combinatória.

Nesse sentido, é importante ressaltar que uma das maiores dificuldades dos alunos com relação à Análise Combinatória está relacionada com a identificação das fórmulas que devem ser utilizadas na resolução de situações-problema propostas e, quando as identificam, utilizam procedimentos errôneos para a sua aplicação (ROA et al., 1997).

Compartilhando este ponto de vista, Rosa (1998) afirma que as dificuldades encontradas pelos alunos na compreensão dos conceitos de Análise Combinatória se devem ao fato de que, frequentemente, as fórmulas lhes são apresentadas antes mesmo que dominem os conceitos combinatórios, pois a sua aplicação está sujeita a um processo mecânico que exclui a compreensão desse conteúdo matemático.

Diante desse quadro, alguns questionamentos começaram a surgir no sentido de como a Modelagem Matemática poderia minimizar os impactos negativos do processo de ensino e aprendizagem de conceitos de Análise Combinatória. Ao se pensar numa possibilidade de pesquisa que incorporasse uma prática de modelagem com o intuito de contribuir com o processo de ensino e aprendizagem da Combinatória refinou-se a seguinte questão de investigação: Como a perspectiva sociocrítica da Modelagem Matemática pode contribuir para o desenvolvimento dos conceitos de Análise Combinatória de alunos do $2^{\circ}$ ano do Ensino Médio de uma escola particular da região do Vale do Rio Doce?

Assim, a partir dessa questão de investigação e da pesquisa desenvolvida, esse artigo tem como objetivo apresentar a Modelagem Matemática como um ambiente de aprendizagem para o processo de ensino e aprendizagem da Análise Combinatória por meio de uma prática em que os alunos visitaram academias de treino para que pudessem verificar se o conhecimento de Análise Combinatória poderia contribuir com o processo de elaboração das fichas de treino, a fim de minimizar o congestionamento de pessoas nas academias e o seu tempo de espera nos aparelhos durante a realização de seus treinos. 
Nesse contexto, apresentam-se a compreensão da Modelagem Matemática como um ambiente de aprendizagem em sua perspectiva sociocrítica, a metodologia e o contexto da pesquisa, com ênfase nos procedimentos metodológicos desenvolvidos no decorrer da condução do trabalho de campo desse estudo. Apresentam-se, também, uma das atividades aplicadas após o momento da visita às academias, bem como a descrição e a análise dos dados e a interpretação de seus resultados. O artigo é finalizado com as considerações finais dos autores e com os possíveis desdobramentos dessa pesquisa para a sua aplicação nas práticas de sala de aula.

\section{Modelagem Matemática como um ambiente de aprendizagem}

Iniciando a discussão sobre uma compreensão da Modelagem Matemática, Barbosa (2001) a definiu como um "ambiente de aprendizagem no qual os alunos são convidados a indagar e/ou investigar, por meio da matemática, situações oriundas de outras áreas da realidade" (p. 6). Assim, por ser uma tarefa que alia a teoria e a prática, a modelagem possibilita a motivação de seus usuários no entendimento de sua própria realidade, estimulando-os na busca de meios para agir sobre esse contexto, transformando-o (BASSANEZI, 2016).

Nesse sentido, por meio da Modelagem, é possível a criação de ambientes de aprendizagem, nos quais os professores atuem como orientadores e mediadores do processo de ensino e das atividades propostas, cabendo aos alunos propor, elaborar, desenvolver e modelar os procedimentos necessários para a construção do conhecimento matemático (ROSA e OREY, 2012). Por exemplo, Barbosa (2003) argumenta que a "matemática [é utilizada] para resolver problemas oriundos de outras áreas do conhecimento" (p. 1) nas atividades curriculares realizadas em salas de aula.

De acordo com Barbosa (2004), discussões a respeito da inclusão de trabalhos de Modelagem Matemática no currículo escolar são realizadas em congressos e conferências nacionais e internacionais. Geralmente, são apresentados cinco argumentos para a inserção da modelagem no processo de ensino e aprendizagem em Matemática: motivação, facilitação da aprendizagem, preparação para utilizar a Matemática em diversas áreas, desenvolvimento de habilidades de exploração e compreensão do papel sociocultural da Matemática.

Nesse sentido, a compreensão do papel sociocultural da Matemática está diretamente vinculada com o interesse na formação de indivíduos para atuarem ativamente na sociedade (BARBOSA, 2004). Por outro lado, Bassanezi (2016) apresenta alguns obstáculos para a utilização 
da Modelagem Matemática no processo de ensino e aprendizagem em Matemática:

\begin{abstract}
Obstáculos instrucionais - Os cursos regulares possuem um programa que deve ser desenvolvido completamente. A modelagem pode ser um processo muito demorado não dando tempo para cumprir o programa todo. Obstáculos para os estudantes -0 uso de Modelagem foge da rotina do ensino tradicional e os estudantes, não acostumados ao processo, podem se perder e se tornar apáticos nas aulas. Obstáculos para os professores - Muitos professores não se sentem habilitados a desenvolver modelagem em seus cursos, por falta de conhecimento do processo ou por medo de se encontrarem em situações embaraçosas quanto às aplicações de matemática em áreas que desconhecem (p. 37).
\end{abstract}

Contudo, esses obstáculos podem ser minimizados quando se modifica o processo clássico de Modelagem, considerando-se o "momento de sistematização do conteúdo e utilizando uma analogia constante com outras situações problemas" (BASSANEZI, 2016, p. 38).

Desse modo, Bassanezi (2016) também argumenta ser importante pensar na Modelagem desenvolvida no processo de ensino e aprendizagem em Matemática como uma estratégia de aprendizagem, que pode estar desvinculado do rigor necessário para a elaboração de modelos matemáticos bem-sucedidos.

Assim, a utilização da Modelagem Matemática como uma estratégia metodológica para esse processo pode ser considerada como um dos caminhos a ser seguido para tornar a aprendizagem em Matemática mais atraente e agradável, pois uma "modelagem eficiente permite fazer previsão, tomar decisões, explicar e entender, enfim, participar do mundo real com capacidade de influenciar em suas mudanças" (BASSANEZI, 2016, p. 177).

Conforme o ponto de vista de Rosa (2010), a motivação para a utilização da Modelagem como uma estratégia metodológica para o processo de ensino e aprendizagem em Matemática é direcionar os alunos a compreenderem os conceitos matemáticos por meio da contextualização de situações-problema que tenham significado no contexto em que são desencadeadas. Essa abordagem possibilita 0 desenvolvimento de uma pré-disposição dos alunos para que possam aprender os conteúdos matemáticos por meio da compreensão de seu valor para auxiliar na resolução de situações-problema enfrentadas no cotidiano.

Nesse direcionamento, a Modelagem Matemática pode ser considerada como um ambiente de aprendizagem que utiliza exemplos da vida cotidiana para facilitar o trabalho pedagógico em sala de aula. Esse ambiente pode ser trabalhado de maneira interdisciplinar quando se estabelecem as relações da modelagem com outras áreas do conhecimento (ROSA e 
OREY, 2003).

De acordo com esse contexto, Rosa e Orey (2012) afirmam que o ambiente de aprendizagem da Modelagem pode ser compreendido como um espaço educacional que contribui para a deflagração da intervenção pedagógica do processo de ensino e aprendizagem em Matemática, pois os professores atuam como mediadores do processo educacional, auxiliando os alunos a expressarem o conhecimento matemático tácito 4 a partir da realização de atividades de Modelagem contextualizadas, como, por exemplo, a elaboração de modelos matemáticos.

\section{Perspectiva Sociocrítica da Modelagem Matemática}

Das perspectivas utilizadas na Modelagem Matemática, a Sociocrítica será empregada com maior ênfase na fundamentação teórica desse artigo, pois privilegia o pensamento crítico sobre o papel e a estrutura dos modelos, bem como reflete sobre a função da Matemática na sociedade moderna.

Como o intento de potencializar a argumentação a favor de uma perspectiva sociocrítica para a Modelagem, é essencial reconhecer que as aplicações da Matemática estão profusamente presentes na sociedade, pois trazem implicações para a vida dos indivíduos. Por exemplo, essa implicação está presente no universo do trabalho, nas áreas científicas, nas tarefas cotidianas, pois a Matemática exerce um papel importante no desenvolvimento da sociedade (BARBOSA, 2003).

Nesse sentido, é indiscutível que o foco da educação seja o de preparar os indivíduos para a participação ativa na sociedade, exercendo o papel de cidadãos ativos e participantes na sociedade. Entretanto, para que isso ocorra, é necessário que os professores visem um processo de ensino e aprendizagem que seja desencadeado a partir da utilização de práticas que permitam que os alunos analisem criticamente os problemas sociais que os rodeiam e que os auxiliem na promoção da justiça social no mundo contemporâneo (ROSA e OREY, 2007).

Desse modo, Rosa e Orey (2007) discutem sobre um processo educacional orientado para a eficiência sociocrítica que adota práticas não tradicionais, pois coloca os alunos no centro do

\footnotetext{
${ }^{4} \mathrm{O}$ conhecimento matemático tácito está relacionado com as maneiras pelas quais os indivíduos utilizam os conceitos matemáticos e se apropriam das experiências matemáticas. Esse tipo de conhecimento está imerso na experiência pessoal e é adquirido e acumulado através da vivência individual, pois envolve fatores intangíveis como crenças, perspectivas, percepções, sistemas de valores, ideias, emoções, normas, pressentimentos e intuições (ROSA e OREY, 2012).
} 
processo de ensino e aprendizagem em Matemática, tornando as salas de aula ambientes que incrementam a sua habilidade criativa e a sua capacidade produtora de conhecimentos matemáticos.

Assim, as atividades de Modelagem, na perspectiva sociocrítica, tornam a sala aula um cosmo em que todos os seus elementos podem participar igualmente, revelando pensamentos e respeitando ideias contrárias, conduzindo os participantes desse processo a observarem como os conteúdos matemáticos e os modelos elaborados podem servir para que os alunos analisem as situações-problema propostas e tomem as decisões com relação aos resultados obtidos nessas investigações (SILVA, KATO e PAULO, 2012).

Nesse contexto, na prática educativa, de acordo com a perspectiva sociocrítica da modelagem,

ambos, professor e alunos, aceitam e assumem o papel de participantes na aprendizagem, através da criação de possibilidades múltiplas para a construção do conhecimento, de um lado por meio de atividades intelectuais relacionadas com investigações, consultas e críticas, e de outro lado, através de atitudes voltadas para a práxis social relacionadas com o diálogo constante, o envolvimento e a comunicação (JACOBINI e WODEWOTZKI, 2006, p. 75).

Assim, a Modelagem pode ser direcionada para a eficiência sociocrítica dos alunos, engajando-os num processo de ensino e aprendizagem contextualizado e com significado. Essa abordagem possibilita que os alunos se incluam na construção social, de modo a atingir um grau de eficiência sociocrítica fundamental para agir de modo ativo em suas comunidades (ROSA e OREY, 2007).

Conforme Barbosa (2006), a expressão Sociocrítica foi relacionada a uma interpretação de Modelagem Matemática que manifesta um esforço para abordar questões concernentes ao papel da Matemática na sociedade mediante a elaboração de atividades de Modelagem propostas em sala de aula.

Desse modo, Almeida e Silva (2010) comentam que a justificativa pela perspectiva sociocrítica está apoiada na constatação de que as atividades de Modelagem podem estimular 0 emprego de situações-problema em que os alunos possam discutir a natureza e a função dos modelos matemáticos na sociedade. 


\section{Metodologia e o contexto da pesquisa}

Na prática de Modelagem Matemática abordada nesse artigo foi utilizado o Caso 2 conforme proposto por Barbosa (2001), em que os professores apresentam uma determinada situação-problema para os alunos investigar por meio da coleta de dados que realizam sobre 0 tema escolhido. Nessa perspectiva, os professores são responsáveis pela condução das tarefas que estão sob a responsabilidade dos alunos.

Nesse contexto, os autores propuseram uma investigação relacionada com a análise combinatória, que visava possibilitar o estudo desse conteúdo a partir de experimentações de situações-problema e atividades interdisciplinares extraclasses que conduziram os alunos para a descoberta de modelos matemáticos que traduziram fenômenos retirados da própria realidade.

A coleta de dados teve início com a divisão dos alunos em três grupos de seis participantes ${ }^{5}$ para a realização dos quatro blocos de atividades propostos em sala de aula inseridos nas três fases da Modelagem Matemática (ROSA, 2005): a) Fase Inicial — Preparação da Modelagem, b) Fase Intermediária - Desenvolvimento da Modelagem e Elaboração de Modelos e c) Fase Final - Apresentação e Avaliação da Modelagem.

Para o desenvolvimento do trabalho de campo dessa pesquisa foram utilizados dois questionários - um inicial e um final -, o diário de campo do professor-pesquisador, uma entrevista semiestruturada com o professor de Educação Física participante desse estudo e quatro blocos de atividades relacionados com as etapas e as fases da Modelagem. 0 Quadro 1 mostra os blocos de atividades do registro documental propostas no estudo.

Quadro 1: Blocos de atividades do registro documental

\begin{tabular}{|c|c|c|}
\hline \multicolumn{3}{|c|}{$\begin{array}{c}\text { BLOCO 1: FASE INICIAL - PREPARAÇÃO DA MODELAGEM } \\
\text { Verificando o conhecimento tácito }\end{array}$} \\
\hline ATIVIDADE & PERÍODO & OBJETIVO \\
\hline $\begin{array}{l}\text { Divisão dos alunos participantes em grupos } \\
\text { de } 6 \text { (seis) componentes para realização de } \\
\text { atividades individuais em sala de aula. } \\
\text { Pesquisa sobre o significado dos conceitos } \\
\text { de análise combinatória. }\end{array}$ & $\begin{array}{l}\text { De } 17 \text { de setembro } \\
\text { de } 2018 \text { a } 9 \text { de } \\
\text { outubro de } 2018 .\end{array}$ & $\begin{array}{l}\text { Verificar a utilização do } \\
\text { pensamento } \\
\text { combinatório adquirido } \\
\text { pelos alunos } \\
\text { participantes em suas } \\
\text { experiências cotidianas } \\
\text { com esse conteúdo } \\
\text { matemático. }\end{array}$ \\
\hline
\end{tabular}

\footnotetext{
${ }^{5}$ Essa atividade de modelagem iniciou com a participação de 18 alunos. Contudo, uma das participantes cancelou a sua participação nesse trabalho, pois se mudou para outra escola.
} 


\begin{tabular}{|c|c|c|}
\hline \multicolumn{3}{|c|}{$\begin{array}{l}\text { BLOCO 2: FASE INTERMEDIÁRIA - DESENVOLVIMENTO DA MODELAGEM } \\
\text { Visita às academias da cidade }\end{array}$} \\
\hline ATIVIDADE & PERÍODO & OBJETIVO \\
\hline $\begin{array}{l}\text { Visita às academias de treino da } \\
\text { cidade para obter informações sobre o } \\
\text { processo de elaboração das fichas de } \\
\text { prescrições de treino. }\end{array}$ & $\begin{array}{l}\text { De } 16 \text { de outubro } \\
\text { de } 2018 \text { a } 29 \text { de } \\
\text { outubro de } 2018 \text {. }\end{array}$ & $\begin{array}{l}\text { Investigar se os alunos } \\
\text { participantes perceberam a } \\
\text { presença dos conhecimentos } \\
\text { matemáticos de análise } \\
\text { combinatória no processo de } \\
\text { elaboração e funcionamento das } \\
\text { fichas de treino. }\end{array}$ \\
\hline \multicolumn{3}{|c|}{ BLOCO 3: FASE INTERMEDIÁRIA - DESENVOLVIMENTO DA MODELAGEM } \\
\hline ATIVIDADE & PERÍODO & OBJETIVO \\
\hline $\begin{array}{l}\text { Análise dos dados coletados nas } \\
\text { pesquisas realizadas sobre as fichas } \\
\text { de prescrições de treino. Investigações } \\
\text { matemáticas das informações obtidas. } \\
\text { Elaboração de modelos baseados nas } \\
\text { fichas de treino. }\end{array}$ & $\begin{array}{l}\text { De } 30 \text { de outubro } \\
\text { de } 2018 \text { a } 19 \text { de } \\
\text { novembro de } 2018\end{array}$ & $\begin{array}{c}\text { Discutir em grupo com a } \\
\text { mediação do professor- } \\
\text { pesquisador a possível conexão } \\
\text { entre os conceitos de análise } \\
\text { combinatória com o processo de } \\
\text { elaboração e funcionamento das } \\
\text { fichas de prescrições de treino. } \\
\text { Elaborar os modelos } \\
\text { matemáticos. }\end{array}$ \\
\hline \multicolumn{3}{|c|}{$\begin{array}{c}\text { BLOCO 4: FASE FINAL - APRESENTAÇÃO DA MODELAGEM E ENTREGA DO RELATÓRIO } \\
\text { FINAL }\end{array}$} \\
\hline \multicolumn{3}{|c|}{ Apresentação dos resultados e avaliação do processo de modelagem } \\
\hline ATIVIDADE & PERÍODO & OBJETIVO \\
\hline $\begin{array}{l}\text { Elaboração do relatório final sobre as } \\
\text { atividades de modelagem relacionadas } \\
\text { com a análise combinatória. } \\
\text { Apresentação dos modelos e dos } \\
\text { resultados obtidos nas pesquisas } \\
\text { realizadas. }\end{array}$ & $\begin{array}{l}\text { De } 26 \text { de novembro } \\
\text { de } 2018 \text { a } 3 \text { de } \\
\text { dezembro de } 2018\end{array}$ & $\begin{array}{l}\text { Discutir sobre a elaboração e a } \\
\text { apresentação do relatório final. } \\
\text { Apresentação do relatório final e } \\
\text { dos modelos elaborados. } \\
\text { Avaliação da apresentação e do } \\
\text { relatório pelos membros da } \\
\text { banca. }\end{array}$ \\
\hline
\end{tabular}

Fonte: Acervo da Pesquisa

O questionário inicial foi aplicado antes da realização dos blocos de atividades e teve como objetivo levantar alguns dados brutos relacionados com o sexo, a idade, o nível econômico, como os alunos se relacionavam com os conteúdos matemáticos estudados e, também, sobre a importância das aulas de Matemática e de seu conteúdo para a resolução de problemas que 
enfrentam no cotidiano.

Na primeira etapa da realização do Bloco de Atividades 1, os alunos participantes foram convidados a realizar 13 atividades com o objetivo de verificar o conhecimento tácito que possuíam sobre os conceitos de Análise Combinatória no contexto de situações-problema cotidianas. Para finalizar o trabalho com esse bloco de atividades, o professor-pesquisador solicitou que os alunos participantes pesquisassem o que é Análise Combinatória, investigando o seu desenvolvimento histórico, os seus conceitos e a sua presença no cotidiano.

Após a apresentação das pesquisas o professor-pesquisador organizou, juntamente com os alunos, a sistematização dos conceitos. Importante destacar que a etapa da sistematização foi importante, uma vez que os alunos necessitariam do conhecimento dos conceitos de Combinatória para o bom desenvolvimento dos demais blocos de atividades.

É importante ressaltar que, concluída a etapa de sistematização dos conceitos, a próxima etapa realizada foi o levantamento de informações sobre como ocorre a confecção das fichas de treino nas academias. Para auxiliá-los nessa compreensão foi solicitado aos dois professores de Educação Física do Ensino Médio para que, durante uma de suas aulas, orientassem e fornecessem informações básicas sobre como é desencadeado os treinos nas academias, bem como sobre a construção das prescrições de treinamento a partir da necessidade de cada indivíduo e de sua condição física.

Essas informações foram discutidas no dia 20 de setembro de 2018, durante a aula desses professores, com a participação do professor de Educação Física participante desse estudo, que também discutiu com os alunos participantes sobre os processos envolvidos na elaboração da prescrição de um treino. Após esse momento, na aula de Educação Física, os alunos participantes, em seus respectivos grupos, elaboraram as questões e formularam as perguntas que serviram de suporte para a investigação nas academias.

Durante o desenvolvimento dos trabalhos, os autores desse artigo decidiram propor para os alunos a criação de um grupo fechado no WhatsApp para facilitar a troca de informações dos assuntos referentes à essa pesquisa. Esse grupo foi formado pelo professor-pesquisador, o administrador do grupo, o seu orientador e os 17 alunos participantes do estudo.

A próxima etapa do trabalho realizada foram as visitas às academias de treinamento. Assim, os alunos participantes de cada grupo escolheram uma academia de sua preferência e realizaram uma entrevista, nos dias 24 e 25 de outubro de 2018, registrando as suas observações 
e informações a respeito da elaboração das fichas de treino. O professor-pesquisador sugeriu que os alunos participantes de cada grupo escolhessem a academia que possuísse uma maior variedade de treinamentos para que pudessem obter uma maior quantidade de exemplos de fichas de treinamento.

Concluída a etapa de visitas, foram propostos oito encontros, sendo um no turno vespertino e os demais no turno matutino, para que os alunos participantes realizassem a análise dos resultados das investigações matemáticas sobre Análise Combinatória dos dados coletados nas academias.

Assim, além das discussões sobre os conceitos matemáticos, outros debates foram realizados nesses encontros, como, por exemplo:

a) Se a ordem de realização dos exercícios num treinamento influencia o resultado esperado.

b) Como as academias funcionam em horários de pico em que o número de pessoas no salão de treinamento é maior que o número de equipamentos disponíveis.

c) A qualidade de prestação do serviço ofertado pelas academias visitadas.

d) O número de instrutores nas academias.

e) Os cuidados que devem ser tomados ao escolher uma academia para treinamento físico.

Ao final desses oito encontros aconteceram outros dois encontros no turno matutino, nos dias 26 e 27 de novembro de 2018, em horário de aula, para a orientação de como os alunos participantes deveriam proceder na realização da última etapa do trabalho. Nesses encontros, esses participantes iniciaram a elaboração do relatório final do trabalho.

É importante ressaltar que, durante a realização dos blocos de atividades, o professorpesquisador filmou as aulas para que não se perdessem informações da conversa dos alunos participantes, bem como de seus gestos e expressões, para que pudesse detectar o que estavam pensando e como estavam agindo com relação à realização das atividades propostas em sala de aula.

Desse modo, o professor-pesquisador solicitou a um participante de cada grupo para que gravasse em áudio, em seu telefone celular, as discussões realizadas em grupos enquanto 
realizava o registro fotográfico quando os alunos participantes realizavam as atividades.

Nesse ambiente de aprendizagem o professor-pesquisador discutiu com os alunos participantes, por meio da realização das atividades contextualizadas dos blocos de atividades, os conteúdos relacionados com a Análise Combinatória e com a utilização da Modelagem Matemática para que, posteriormente, observassem a sua relação com o cotidiano.

Nesse direcionamento, o registro das observações realizadas durante a realização das atividades matemáticas curriculares propostas em sala de aula foi realizado no diário de campo do professor-pesquisador imediatamente após a aplicação dessas atividades para os alunos participantes dessa pesquisa. O professor-pesquisador também transcreveu os vídeos e áudios que foram realizados durante a condução dessas atividades.

O questionário final foi entregue para os alunos responderem, no dia 3 de dezembro de 2018, após a realização das atividades do registro documental propostas para a sala de aula. 0 principal objetivo desse questionário foi identificar se os alunos entenderam os conceitos de Análise Combinatória, compreenderam como relacionar esse conteúdo ao cotidiano e se a perspectiva sociocrítica da Modelagem Matemática contribuiu para esse processo, auxiliando-os no desenvolvimento de sua criticidade e reflexão.

\section{Descrição e análise das atividades aplicadas após a visita às academias}

A aplicação do Bloco de Atividades 3: Fase intermediária - desenvolvimento da Modelagem iniciou-se no dia 30 de outubro de 2018, sendo finalizada no dia 19 de novembro de 2018. Esse bloco foi composto pela aplicação de duas folhas de atividades nos encontros realizados nos dias 30 de outubro de 2018 a 13 de novembro de 2018.

O objetivo dessas atividades foi conectar o conhecimento de Análise Combinatória desenvolvido nas tarefas realizadas no Bloco de Atividades $1 \mathrm{com}$ as atividades da análise das fichas, procurando verificar se os alunos participantes conseguiriam identificar a presença de conhecimentos combinatórios no momento das prescrições dos treinos, bem como na elaboração de modelos matemáticos relacionados com essa temática..

Desse modo, o encontro realizado no dia 30 de outubro de 2018 se iniciou com a solicitação do professor-pesquisador para que os participantes se reunissem em grupos de acordo com a formação utilizada na visita às academias. Após a entrega da folha de atividades 0 
professor-pesquisador solicitou que os alunos lessem o texto inicial que trazia informações sobre a modalidade de treinamento em circuito de acordo com um profissional de Educação Física.

A análise dos registros anotados no diário de campo do professor-pesquisador revela que todos os participantes ficaram em silêncio e estavam concentrados durante a leitura do texto inicial. Passados dez minutos do início do encontro, o professor-pesquisador promoveu a discussão com os participantes a respeito do treinamento em circuito abordado no texto lido por eles. O Quadro 2 mostra alguns trechos da reflexão realizada pelo professor-pesquisador sobre a modalidade de treinamento em circuito abordado no texto lido pelos alunos participantes.

\section{Quadro 2: Discutindo a modalidade de treinamento em circuito}

Professor-pesquisador: Vocês viram aí que nessas duas folhas, que o treinamento em circuito é uma das modalidades que se tem na academia. Aí nesse caso, o profissional apresenta uma modalidade de treinamento em circuito para quem deseja emagrecer e não tem muito tempo de frequentar uma academia. Aí, ele faz a proposta de cinco exercícios e vai explicando o que vai fazer, como executar os cinco exercícios. Aí, ele mostra que no primeiro exercício a pessoa tem a opção de fazer 30 segundos de corda naval, que é muito usada no treinamento funcional. Se na academia não tiver a corda naval a pessoa pode fazer 30 segundos de flexão no chão. Aí, ele explica que quando você fizer esse exercício você tem que encostar o peitoral no chão de forma muito rápida, tem que ser com intensidade alta. Aí, o segundo exercício é 30 segundos em escada. No vídeo que eu assisti desse profissional, o endereço do site está aí na fonte, ele mostra que lá no estúdio dele tem uma escada de acesso que ele usa para fazer esse exercício. Aí, a pessoa vai subindo e descendo bem rapidamente. O terceiro exercício, chamado de Squat, usa bag ou anilha. Esse tipo de exercício é tipo um agachamento feito na musculação. A pessoa coloca o peso nas costas e faz 0 agachamento. $O$ quarto exercício é indicado para o fortalecimento do abdômen. Ele pode ser feito diretamente no chão, movimentando as pernas de maneira bem rápida. $\mathrm{E} o$ último exercício que são 30 segundos no transport, mais conhecido como elíptico. Aí, ele fala que nesse treino, esses exercícios são executados em quatro rounds. Quer dizer que a pessoa faz os cinco exercícios, terminou faz de novo os cinco exercícios, quatro vezes. Esse é 0 treino em circuito. Aí, ele vai falar dos benefícios desse tipo de treinamento, melhora o condicionamento físico, resistência, potência. Ele fala que o tempo máximo de espera de um treinamento em circuito é o tempo de deslocamento de um indivíduo de um equipamento para outro. Quer dizer, não tem essa história de ficar esperando aparelho vagar, não tem essa de ficar demorando entre um exercício e outro, é jogo rápido.

\section{Fonte: Acervo da Pesquisa}

Logo após a sua explanação, o professor-pesquisador perguntou se os participantes tinham alguma dúvida sobre o funcionamento do treinamento em circuito. $A$ análise das anotações registradas em seu diário de campo mostra que os participantes não tiveram dúvidas sobre esse assunto. Em seguida, o professor-pesquisador solicitou que os alunos participantes resolvessem as questões da folha de atividades que se relacionavam com essa modalidade de treino.

A análise desses registros também mostra que todos os alunos participantes estavam presentes nesse encontro e se envolveram ativamente na resolução dessas atividades. A Figura 
1 mostra os participantes dos grupos Hexa, Esquadrão da Matemática e Federal trabalhando na resolução das atividades propostas na folha de atividades.

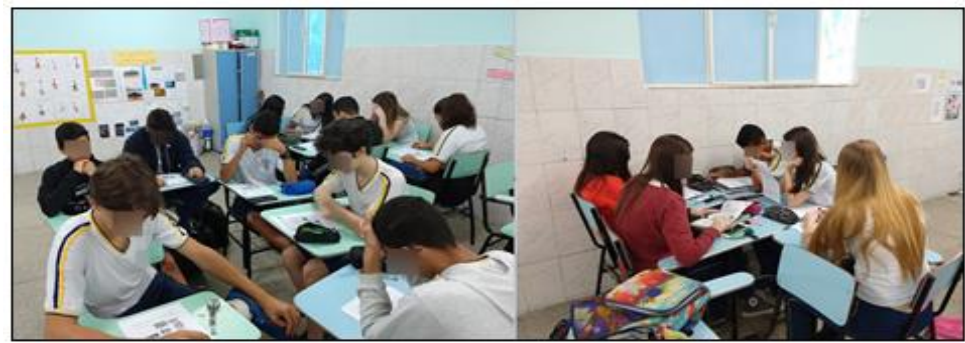

Figura 1: Resolução da folha de atividades pelos participantes dos grupos Hexa, Federal e Esquadrão da Matemática (Acervo da Pesquisa)

O quadro 3 mostra o diálogo dos participantes do grupo Federal sobre a resolução da letra A da questão: De quantas maneiras essa academia pode organizar esse circuito de treinamento?

Quadro 3: Discutindo a resolução da questão sobre a análise das prescrições das fichas de treino

\section{F14: Tem cinco maneiras.}

F10: Pra mim é só uma. Uai, só tem um aparelho velho.

F16: Tipo assim, se tiver cinco pessoas, quatro pessoas vão fazer os outros treinamentos. Mas se tiver mais não vai dar certo.

F10: Mas eu não sei, tipo assim, por exemplo, tem que começar com esse [exercício]. Então, tipo assim, não pode começar com outros?

F16: Mas a primeira pessoa pode ir primeiro no Climber. Eu acho que a ordem não importa.

F10: A ordem importa, ele falou aqui ó qual que é o primeiro, qual que é o segundo. Eu acho que é assim, tem cinco pessoas, quando um acabar aqui o outro vem e vai pra cá. E por aí vai.

F16: Será que é arranjo?

F10: Você acha o que? A ordem importa ou não?

F6: Pra mim não.

F12: Pra mim eu acho também que não.

M13: É uma permutação.

F10: Por quê?

M13: Porque você vai fazer uma troca.

F10: Mas aqui ele falou velho qual é o primeiro exercício até o último.

M13: Não, esses aqui são os exercícios. Essa é a ordem que ele escolheu, mas na hora de fazer o rodízio não importa.

F10: Mas não tem que seguir essa ordem não?

M13: Não, a ordem não importa.

F16: É porque se não a academia não ia funcionar.

M13: Vai ser permutação normal. 
F10: Qual que é a fórmula mesmo?

M13: $N$ fatorial. $P$ igual a 5 fatorial.

F16: Vai dar 120.

\section{Fonte: Acervo da Pesquisa}

A análise das respostas dadas para a letra $A$ dessa questão mostra que 16 alunos participantes encontraram a resposta correta por meio da utilização do conceito de permutação. Por outro lado, 2 (dois) alunos participantes enunciaram de maneira errônea a fórmula de permutação. Por exemplo, as Figuras 2 e 3 mostram a resolução das participantes $F 20$ e $F 6$ para essa questão. Essas duas participantes encontraram a resposta correta, contudo, a participante F20 utilizou erroneamente a fórmula de permutação.

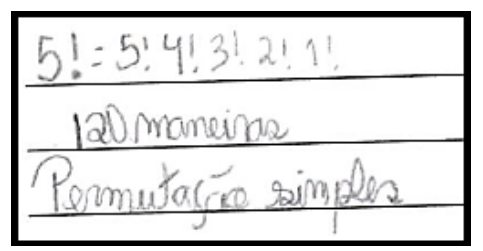

Figura 2: Resolução da letra A pela participante F20 (Acervo da Pesquisa)

$$
\begin{aligned}
& P_{5}=5 ! \\
& P_{5}=5 \cdot 4 \cdot 3 \cdot 2 \cdot 1=120 \text { maneix ar }
\end{aligned}
$$

Figura 3: Resolução da letra A pela participante F6 (Acervo da Pesquisa)

A análise das respostas dadas pelos alunos participantes para a letra $B$ da questão Como é possivvel determinar o total de pessoas que podem ser matriculadas numa sessão de treinamento em circuito? Explique -, mostra que 16 alunos participantes responderam corretamente essa questão. Contudo, 3 (três) desses alunos participantes não explicaram como determinaram a sua resposta. A Figura 4 mostra a reposta dada pela participante F12, do grupo Federal, para essa questão.

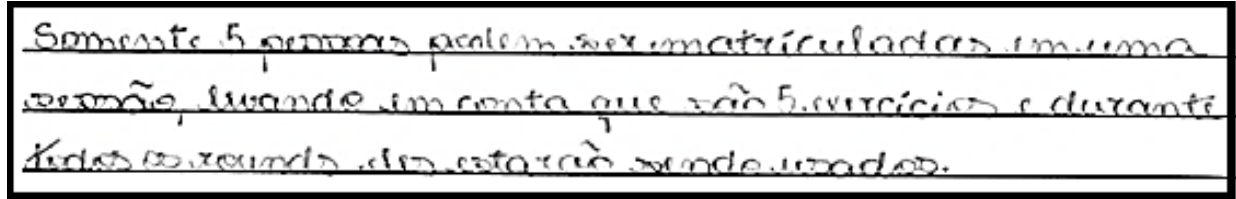

Figura 4: Resolução da letra B pela participante F12 (Acervo da Pesquisa)

A análise dessas respostas também mostra que o participante M9 respondeu essa questão erroneamente, pois afirmou que "Pode-se dividir em grupos de 0 ou 15 pessoas e os horários podem ser divididos pelo tempo de cada circuito". 
Prosseguindo com o processo de análise das respostas dadas pelos participantes para letra a $C$ da questão - $O$ proprietário dessa academia se propõe a oferecer esse serviço para os seus clientes em pacotes mensais, sendo dois treinos semanais, que ocorrerão no período de 8 horas às 9 horas da manhã ou das 16 horas às 17 horas, na segunda-feira e sexta-feira de cada semana. Determine o número máximo de pessoas que frequentarão essa modalidade por semana. Considere a possibilidade de lotação máxima em todas as sessões -, mostra que 6 (seis) participantes responderam corretamente essa questão. A Figura 5 mostra a resolução realizada pelo participante M11 que respondeu corretamente essa questão.

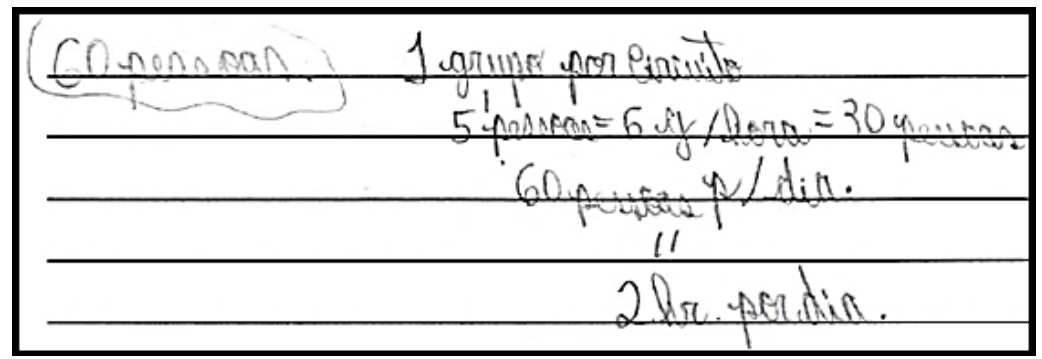

Figura 5: Resolução do participante M11 para a letra C (Acervo da Pesquisa)

A análise das anotações registradas no diário de campo do professor-pesquisador mostra que os 11 participantes que erraram a questão mostraram dificuldades na compreensão do enunciado. Por exemplo, o Quadro 4 mostra o diálogo entre os participantes F4 e M15 sobre a interpretação do enunciado dessa questão.

Quadro 4: Discutindo o enunciado da letra $C$

F4: Eu acho que está perguntando a lotação máxima no fim e não quantas pessoas foram. Ele quer saber quantas pessoas tinham no máximo em todas as sessões. Não perguntou se tal pessoa fez duas vezes.

M15: Está perguntando quantas pessoas foram no máximo. Foi uma pessoa duas vezes.

F4: Tem que considerar que uma pessoa foi duas vezes? Eu acho que não. Está perguntando lotação máxima.

M15: Eu acho que sim.

F4: Não está perguntando quantas pessoas foram. Está perguntando a lotação máxima no fim, de todas as sessões. Quantas pessoas tinham no máximo em todas as sessões. Não perguntou se tal pessoa foi duas vezes. No fim ela foi? É isso que está perguntando.

$$
\text { Fonte: (Acervo da Pesquisa) }
$$

A análise das anotações registradas no diário de campo do professor-pesquisador mostra que a participante $F 20$ questionou o professor-pesquisador afirmando que a questão estava má formulada, pois era ambígua. A Figura 6 mostra a resolução dessa questão por essa participante. 


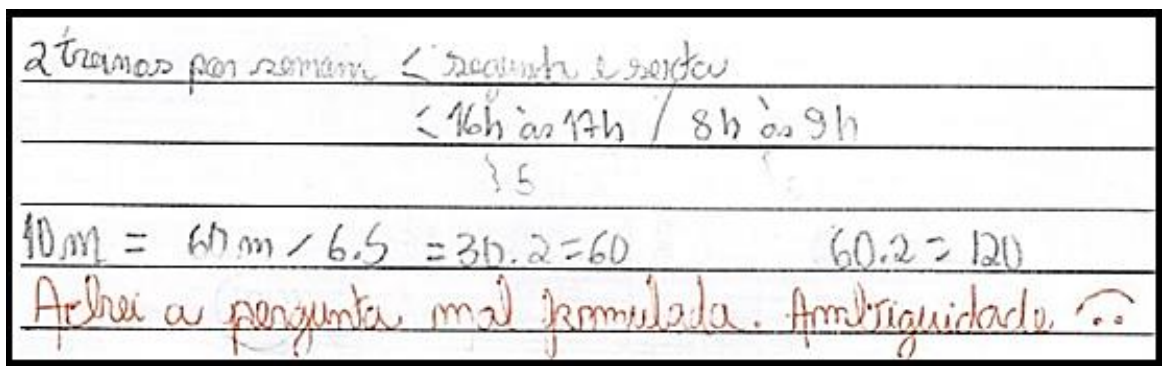

Figura 6: Resolução da letra C pela participante F20 (Acervo da Pesquisa)

A análise das respostas dadas para a questão - Como é possível determinar o número máximo de pessoas que podem ser matriculadas numa sessão de treinamento em circuito, considerando que ninguém fique ocioso? - mostra que 10 alunos participantes resolveram essa questão corretamente. Por exemplo, o participante $M 1$ respondeu que o "número máximo de pessoas, sem ninguém ficar ocioso é 10". A Figura 7 mostra a estratégia utilizada por esse participante na resolução dessa questão.

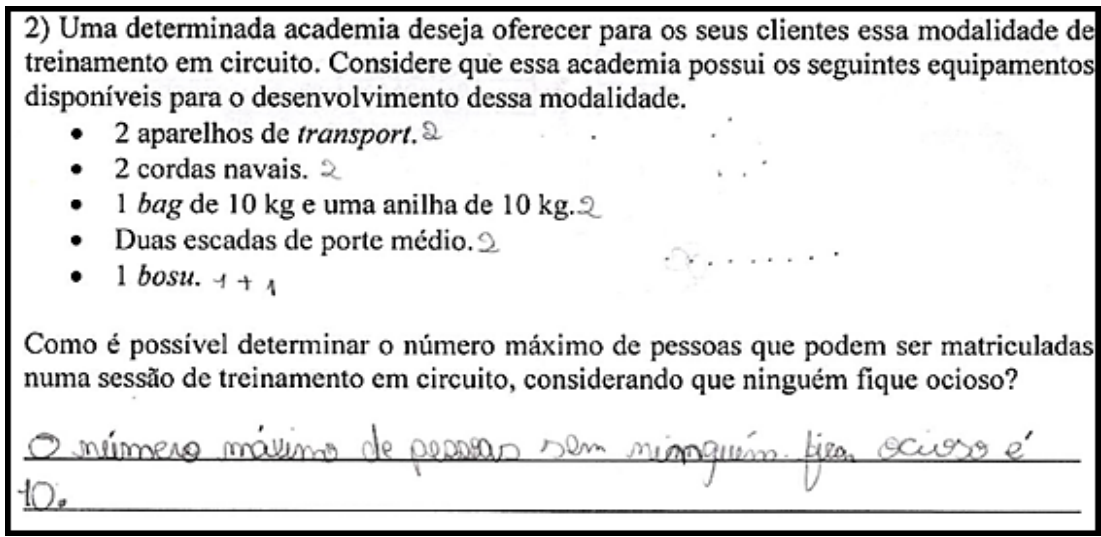

Figura 7: Resolução da questão pelo participante $M 1$ (Acervo da Pesquisa)

Contudo, a análise dos resultados mostra que 7 (sete) participantes erraram a resolução da questão por não considerarem que o exercício Mountain Climber pode ser realizado utilizando o bosu, ou seja, diretamente no chão6. Por exemplo, a participante F16 respondeu que o "número máximo de pessoas que podem ser matriculadas numa sessão de treinamento em circuito, de acordo com a quantidade de aparelhos disponíveis, é igual a nove".

A análise das respostas para a questão Um estúdio de treinamento funcional oferece aos seus clientes uma modalidade adaptada de treinamento em circuito para emagrecimento. Como não há disponibilidade de uma escada para a execução do $2^{\circ}$ exercício no momento, o proprietário do estúdio deseja substituir esse exercício por 30 segundos na bicicleta e 20 segundos de corrida

\footnotetext{
${ }^{6}$ Essa informação constava no texto inicial que tratava de um treinamento na modalidade de circuito.
} 
na esteira. De quantas maneiras o proprietário do estúdio pode montar esse circuito? Explique, mostra que 12 alunos participantes resolveram corretamente essa questão. A Figura 8 apresenta a resolução da participante $F 8$ que respondeu corretamente à questão utilizando-se do conceito de permutação.

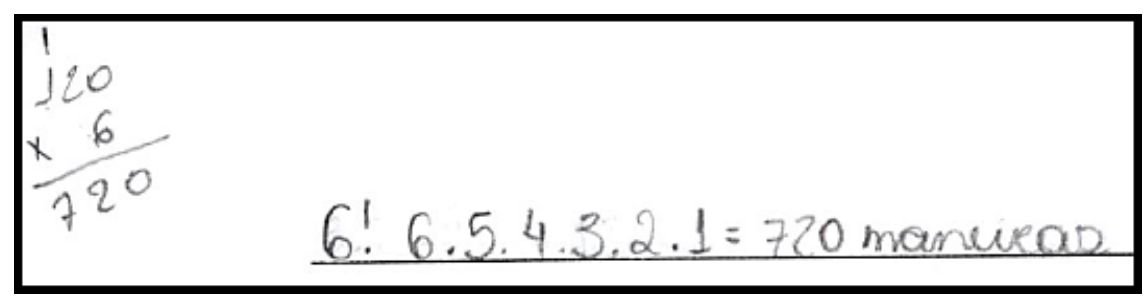

Figura 8: Resolução da questão pela participante F8 (Acervo da Pesquisa)

Em contrapartida, 5 (cinco) alunos participantes resolveram essa questão erroneamente por não considerarem que o segundo exercício do circuito de treino foi substituído por dois exercícios, 30 (trinta) segundos na bicicleta e 20 (vinte) segundos de corrida na esteira7 ${ }^{7}$ Por exemplo, o participante M11 justificou a sua resposta respondendo que "a quantidade de exercícios é a mesma". A Figura 9 mostra a resolução realizada por esse participante.

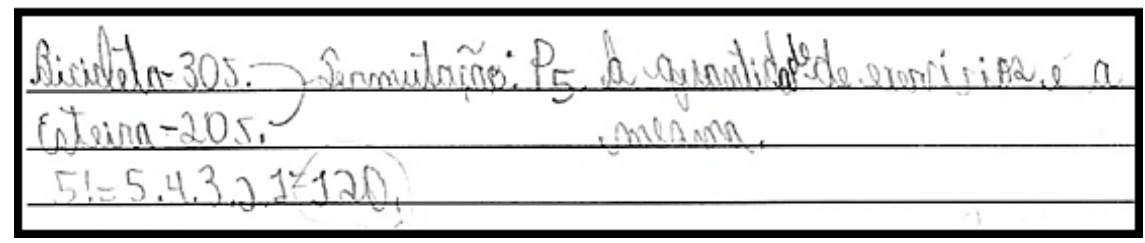

Figura 9: Resolução da questão pelo participante M11 (Acervo da Pesquisa)

A análise das respostas dadas para a letra $A$ da questão Considerando apenas os treinamentos de segunda-feira, quantas fichas diferentes de podem ser prescritas pelo instrutor dessa academia para os treinamentos de bíceps e costas, considerando que não haverá rodízio de aparelhos entre os alunos e que os exercícios serão executados na ordem que é apresentado na ficha? Registre todos os seus cálculos, mostra que 8 (oito) alunos participantes resolveram a questão enquanto 9 (nove) não a responderam.

Dentre os 8 (oito) alunos participantes que resolveram essa questão, somente a participante F2 a resolveu corretamente, pois 7 (sete) participantes utilizaram 0 conceito de combinação para resolvê-la. As Figuras 10 e 11 mostram, respectivamente, as estratégias utilizadas pelos participantes F2 e M11 na resolução dessa questão.

\footnotetext{
${ }^{7}$ Essa informação constava no texto inicial que tratava de um treinamento na modalidade de circuito.
} 


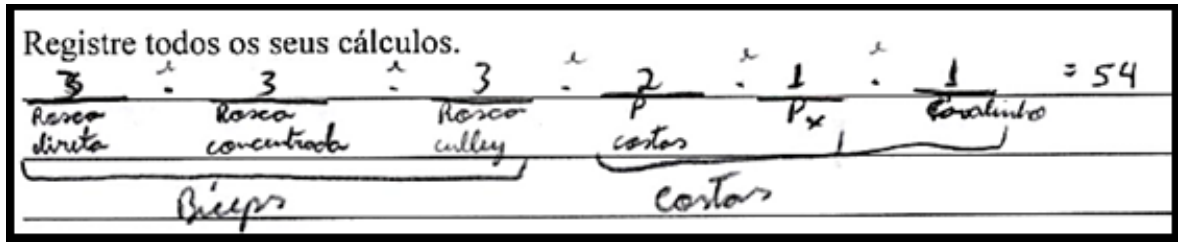

Figura 10: Estratégia ${ }^{8}$ utilizada pela participante F2 (Acervo da Pesquisa)

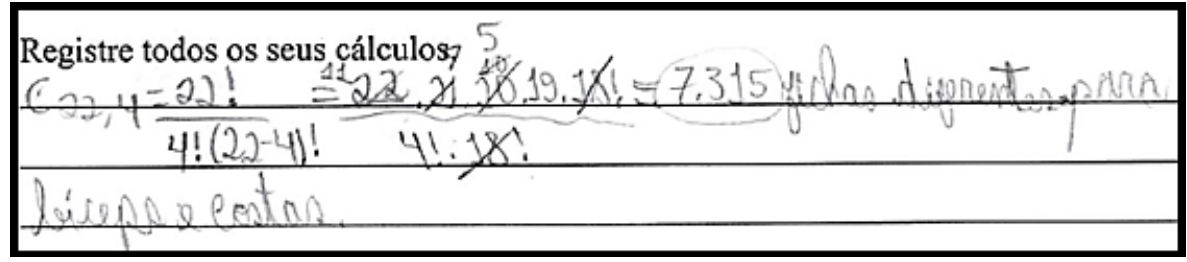

Figura 11: Resolução da questão pelo participante M11 (Acervo da Pesquisa)

A análise das respostas dadas para a letra $B$ da questão $E$ possível utilizar algum dos conceitos de análise combinatória para resolver a questão anterior? Explique, mostra que 12 alunos participantes resolveram essa questão enquanto 5 (cinco) não a responderam. Quando questionados pelo professor-pesquisador sobre esse fato, esses participantes comentaram que não tinham entendido as informações dadas pela questão, portanto, não sabiam como deveriam resolvê-la.

Dentre os alunos participantes que resolveram essa questão, 3 (três) a responderam corretamente. Por exemplo, a participante F4 respondeu que é "arranjo, pois a ordem importa". Dentre os participantes que responderam corretamente a letra $B$, duas alunas participantes, $F 4 \mathrm{e}$ F8, não resolveram a letra $A$.

A análise das respostas dadas pelos participantes para a questão Uma academia possui 5 esteiras e 6 bicicletas para aquecimento e treinamento cardiorrespiratório. Cinco pessoas chegam a academia e desejam fazer o aquecimento em um dos aparelhos antes do treino de musculação. Sabendo que no momento, estão ocupadas 3 esteiras e 2 bicicletas, de quantas maneiras diferentes as cinco pessoas podem fazer o aquecimento? Explique, mostra que 11 participantes responderam corretamente essa questão, justificando a sua resposta por meio da utilização da fórmula de combinação. A Figura 12 mostra a resolução da questão pela aluna participante F8.

\footnotetext{
${ }^{8}$ A participante F2 utilizou o princípio fundamental da contagem na resolução dessa questão.
} 


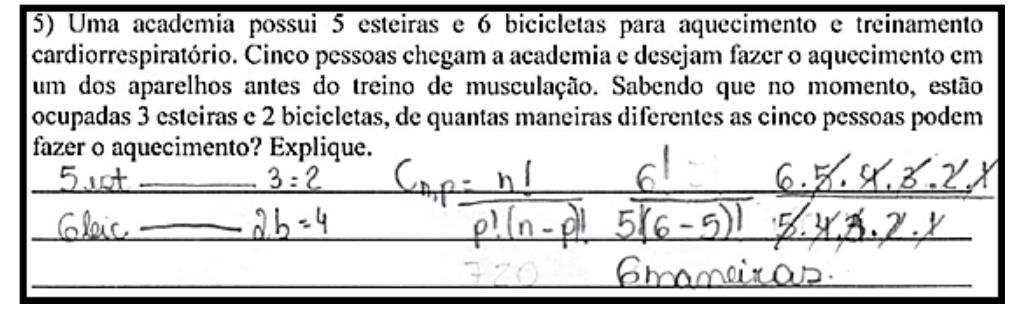

Figura 12: Estratégia utilizada pela participante F8 (Acervo da Pesquisa)

A análise das respostas para essa questão também mostra que 5 (cinco) alunos participantes cometeram erros ao resolvê-la enquanto 1 (um) participante não a resolveu. A Figura 13 mostra a solução de um dos participantes que erraram a questão ao recorrer dos conceitos de permutação para determinar a resposta para a questão.

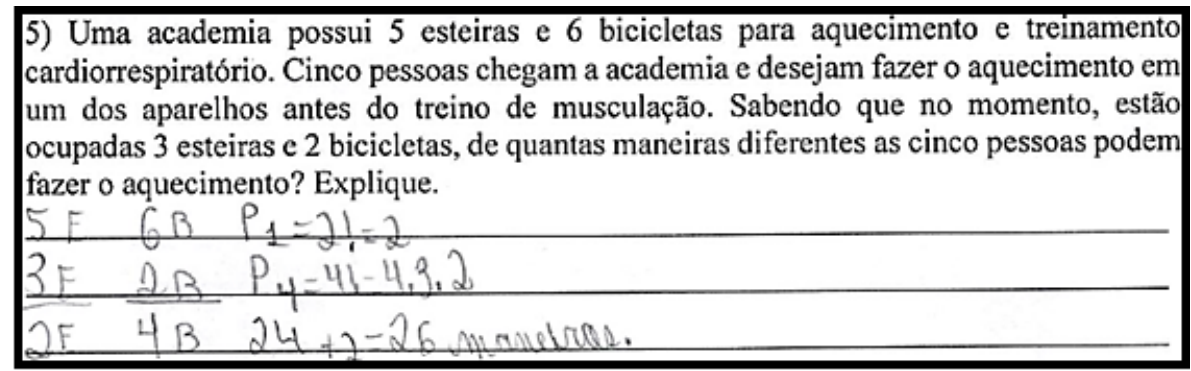

Figura 13: Resolução da questão pelo participante M11 (Acervo da Pesquisa)

Concluindo o processo descritivo e analítico dessas atividades, a análise das respostas dadas para a questão Considere que no horário das 18:00 até às 22:00 uma academia possua um público de 200 pessoas malhando no salão de musculação. Tomando como referência o número de instrutores dessa academia (5 instrutores no salão de musculação no período considerado) e a média de alunos que cada um deles atende, você acredita ser possível garantir um bom atendimento nessa academia? Comente, mostra que todos os 17 alunos participantes responderam essa questão.

Refletindo a respeito da qualidade do atendimento oferecido por essa academia 0 participante $M 15$ respondeu que "É impossível garantir um bom atendimento, uma vez que um profissional seria capaz de atender a no máximo 20 alunos, como vimos na visita à academia. $\mathrm{E}$ possível perceber que a qualidade do serviço prestado por essa academia não é bom".

Com relação às impressões dos 17 alunos participantes sobre 0 atendimento nas academias ao tomarem como referência o número de instrutores e a média de clientes que cada um deles atende, esses participantes se conscientizaram sobre a impossibilidade da garantia de um bom atendimento nesses ambientes. 
Por exemplo, o participante M13 argumentou que "Eu acredito que é impossivel de se ter um bom atendimento nessa academia, visto que a média dos de alunos por instrutor é de quarenta alunos. É, humanamente, bem difícil, quase impossível uma pessoa poder ajudar quarenta". Similarmente, a aluna participante F4 comentou que "com o grande número de alunos por instrutor, estes acabam por não conseguir dar atenção e fiscalizar todos os alunos e, muitos desses acabam sem auxílio e fazendo movimentos de forma errada".

De acordo com a interpretação dos resultados obtidos nas atividades, infere-se que esses participantes discutiram criticamente sobre os principais aspectos relacionados com a elaboração das fichas de prescrição de treino, bem como sobre o funcionamento das academias e a função dos instrutores, conectando-a com as situações-problemas vivenciadas nesse ambiente.

\section{Considerações}

Nesse artigo apresentaram-se recortes de uma pesquisa de mestrado profissional em Educação Matemática e discutiu-se a respeito de como a aplicação da Modelagem Matemática na Educação Básica, por meio de sua perspectiva sociocrítica, pode contribuir para o processo de ensino e aprendizagem dos conceitos de Análise Combinatória.

Compreende-se que a busca por caminhos metodológicos inovadores, que visam integrar o cotidiano dos alunos com o fazer matemático, possibilita um vínculo entre a estrutura lógicoformal da Modelagem Matemática com a sua utilização em salas aula, pois procura compreender e descrever a realidade, propiciando para os alunos participantes desse estudo a percepção de terem uma participação central e atuante no processo de ensino e aprendizagem em Matemática.

Nas atividades de Modelagem realizadas, durante a condução do trabalho de campo desse estudo, o professor-pesquisador realizou intervenções pedagógicas quando surgiram conteúdos matemáticos desconhecidos para os participantes, explicando-os e esclarecendo-os e, além disso, buscou relacionar os conteúdos contemplados no currículo matemático acadêmico, que surgiram no contexto da realização desse projeto de Modelagem, com as atividades realizadas fora do contexto escolar.

Nessa abordagem, os alunos participantes participaram ativamente na realização das atividades propostas no decorrer da condução do trabalho de campo desse estudo, discutindo sobre a elaboração das respostas às questões propostas nas atividades. Nesse sentido, é 
importante destacar que, para o bom desenvolvimento de uma prática de Modelagem em sala de aula, é fundamental que as situações-problema propostas sejam advindas de temas e contextos que partem da realidade dos alunos.

Então, nesse estudo, a proposta de investigar os processos de elaboração das fichas de prescrição de treinos nas academias foi feita pelo professor-pesquisador, após uma sondagem realizada junto aos alunos participantes desse estudo, ao indicarem que esse tema despertava 0 seu interesse e a sua motivação.

Contudo, para que uma nova disposição educacional seja efetivada nas instituições de ensino, é necessária uma reconstrução do sabe/fazer escolar para que essa ação pedagógica seja desenvolvida de uma maneira criativa e reflexiva, por meio da qual os alunos aprendam os conteúdos matemáticos relacionados com a Análise Combinatória por meio da resolução de situações-problema cotidianas relacionadas com a realidade de suas comunidades.

Desse modo, existe a necessidade de ressaltar a importância de humanizar a Matemática em seu processo de ensino e aprendizagem, inserindo valores, como, por exemplo, o social, o político e o econômico, para auxiliar os alunos a se tornarem cidadãos ativos em sua trajetória educacional (ROSA e OREY, 2016).

De acordo com esse contexto, a Modelagem Matemática pode ser considerada como parte de uma ação pedagógica que possibilitou a definição de estratégias de ação que ofereceram para os participantes desse estudo as condições necessárias para a análise de fenômenos diários relacionados com o ambiente extraescolar das academias, que visavam à construção de um saber/fazer contextualizado no cotidiano das academias e, também, na Matemática escolar.

Ressalta-se que o principal objetivo da realização dos Blocos de Atividades 2, 3 e 4, num contexto de ensino direcionado para a eficiência sociocrítica, propiciou que os alunos participantes desse estudo vivenciassem uma ação pedagógica por meio da realização de atividades de Modelagem Matemática fundamentadas no ambiente extraescolar das academias.

Essa ação pedagógica propiciou o reconhecimento da presença de conhecimentos matemáticos de Análise Combinatória na elaboração das fichas de prescrições de treinamento físico de musculação realizada nas academias, em um contexto extraescolar, mostrando, assim, a conexão do currículo matemático escolar com o cotidiano, no caso desse estudo, relacionado com as academias. 
Então, por meio da perspectiva sociocrítica da Modelagem Matemática, os alunos participantes obtiveram informações técnicas com relação ao processo da elaboração das fichas de prescrição de treinos nas academias, que propiciou a conscientização sobre a presença, ainda que indiretamente, dos conceitos combinatórios necessários para a construção dessas fichas.

Os resultados obtidos nesse estudo mostram as contribuições da perspectiva sociocrítica da Modelagem Matemática para a promoção de discussões críticas e reflexivas sobre o papel dos modelos matemáticos no ambiente extraescolar das academias. Assim, a finalidade dessa abordagem estava relacionada com a proposição de soluções para uma melhor gestão dos treinos nas academias a partir de treinamentos na modalidade de circuito e o descongestionamento dos aparelhos utilizados pelos clientes.

Nesse sentido, a partir da interpretação dos resultados obtidos nas atividades do trabalho de campo, conclui-se que os alunos participantes estabeleceram uma discussão crítica e reflexiva a respeito dos aspectos relacionados com a elaboração das fichas de treino, bem como sobre a gestão dos treinos nas academias e o papel dos instrutores (BASTOS e ROSA, 2019).

Desse modo, de acordo com Barbosa (2004), a atividade de Modelagem Matemática em sala de aula deve estimular os alunos a discutir os conceitos matemáticos e o papel do conhecimento matemático no contexto de eventos do cotidiano, de outros saberes/fazeres e de outros campos do conhecimento.

Nesse estudo, ao se referir sobre à Modelagem como uma ação pedagógica para 0 processo de ensino e aprendizagem de Análise Combinatória, essa pesquisa ganhou maior relevância no campo de pesquisa em Educação Matemática, uma vez que são raras as investigações que abordam, de uma maneira abrangente, essa temática.

Por exemplo, na pesquisa bibliográfica realizada no banco de teses da Coordenação de Aperfeiçoamento de Pessoal de Nível Superior (CAPES), em março de 2018 e, repetida em dezembro de 2019, a procura de resumo de dissertações e teses que discutissem o tema dessa pesquisa sob as palavras-chave relacionadas como, por exemplo, Modelagem Matemática, Ensino de Análise Combinatória e Educação Matemática, foi encontrado apenas o registro de uma pesquisa conduzida por Brumano (2014), que abordou essas temáticas numa prática de Modelagem em que os participantes analisaram o funcionamento de um restaurante self-service.

Dessa maneira, Rosa (2010) argumenta que a ação pedagógica da Modelagem Matemática para o processo de ensino e aprendizagem de conteúdos matemáticos tem relevância 
no resultado das relações dos alunos com o seu ambiente por intermédio de professores que buscam mediar o desenvolvimento dessa prática escolar.

Com referência ao conhecimento combinatório na docência, o resultado dos estudos conduzidos por Alves (2012), Ambrozi (2017), Sabo (2010) e Santos (2011) apontam críticas sobre a maneira como os professores se relacionam com os conteúdos matemáticos da Análise Combinatória no desenvolvimento de suas práticas pedagógicas de sala de aula. Nesse direcionamento, as dificuldades encontradas pelos professores ao ensinar os conceitos de Análise Combinatória podem estar relacionadas com a lacuna em sua formação docente referente ao processo de ensino e aprendizagem desse conteúdo matemático específico.

Por exemplo, de acordo com Sabo (2010), os tópicos de Análise Combinatória, quando trabalhados em cursos de formação continuada, estão relacionados com as aplicações desses conceitos para a compreensão de tópicos da disciplina de Estatística. Para Alves (2012), as dificuldades encontradas pelos professores de Matemática no ensino de conteúdos combinatórios estão fundamentadas na capacidade de possibilitar que os alunos desenvolvam um raciocínio lógico para interpretar as situações-problema propostas em sala de aula. Nesse contexto, a aprendizagem desse conceito é desencadeada de maneira mecânica sem a apreensão conceitual desse conteúdo.

Assim, as escolhas didáticas e pedagógicas realizadas pelos professores, ao ensinarem os conceitos de Análise Combinatória, são influenciadas pelas suas experiências com esses conteúdos em sua formação escolar e, também, durante o seu processo formativo. Nesse sentido, é primordial que os cursos de formação de professores abordem, discutam e construam possibilidades para o processo de ensino e aprendizado desses conceitos (SABO, 2010).

Nesse contexto, essa investigação mostrou que a experiência de Modelagem conduzida nesse estudo para o desenvolvimento dos conceitos de Análise Combinatória pode ser considerada como um referencial didático e pedagógico relevante para que os professores possam inovar as suas práticas com relação a esse conteúdo matemático.

\footnotetext{
${ }^{9}$ A dissertação que originou esse trabalho assim como o produto educacional se encontram disponíveis para consulta e download no portal do Programa de Pós-Graduação em Educação Matemática da Universidade Federal de Ouro Preto, a partir do link http://www.ppgedmat.ufop.br.
} 


\section{Referências}

ALMEIDA, Lourdes Maria Werle; SILVA, André. Por uma educação matemática crítica: a modelagem matemática como alternativa. Educação Matemática Pesquisa, São Paulo, v. 12, n. 2, p. 221-241, maio/ago. 2010.

ALVES, Renato de Carvalho. O ensino de Análise Combinatória na Educação Básica e a formação de professores. 2012. 161f. Dissertação (Mestrado Ensino de Matemática) - Instituto de Matemática. Universidade Federal do Rio de Janeiro. Rio de Janeiro.

AMBROZI, Luiz. Jogos em uma sequência didática para o ensino de Análise Combinatória. 2017. 162f. Dissertação (Mestrado em Ensino de Ciências e Matemática) - Área do Conhecimento de Ciências Exatas e Engenharias. Universidade de Caxias do Sul. Caxias do Sul.

BARBOSA, Jonei Cerqueira. Mathematical modelling in classroom: a social-critical and discursive perspective. ZDM, v. 38, n. 3, p. 293-301, 2006.

BARBOSA, Jonei Cerqueira. Modelagem matemática e a perspectiva sócio-crítica. In: II SEMINÁRIO INTERNACIONAL DE PESQUISAS EM EDUCAÇÃO MATEMÁTICA, 2003, Santos. Anais do II SIPEM. Santos: SBEM, 2003, p. 1-13.

BARBOSA, Jonei Cerqueira. Modelagem matemática na sala de aula. In: VIII ENCONTRO NACIONAL DE EDUCAÇÃO MATEMÁTICA, 2004, Recife. Anais do VIII ENEM - Educação Matemática: um compromisso social. Recife: SBEM, 2004, p. 1-10.

BARBOSA, Jonei Cerqueira. Modelagem na Educação Matemática: contribuições para o debate teórico. In: 24ª REUNIÃO ANUAL DA ANPED, 2001, Caxambu. Anais da $24^{a}$ ANPED. Santos: ANPED, 2001, p. 1-15.

BASSANEZI, Rodney Carlos. Ensino-aprendizagem com Modelagem Matemática. 4. ed. São Paulo: Contexto, 2016.

BASTOS, Ticiano Azevedo; ROSA, Milton. Uma experiência de Modelagem Matemática no desenvolvimento de conceitos de Análise Combinatória. In: XI CONFERÊNCIA NACIONAL SOBRE MODELAGEM NA EDUCAÇÃO MATEMÁTICA, 2019, Belo Horizonte. Anais do XI CNMEM - Modelagem Matemática na Educação Matemática e a escola brasileira: atualidades e perspectivas. Belo Horizonte: UFMG, 2019, p. 1-15.

BRUMANO, Cleuza Eunice Pereira. A Modelagem Matemática como metodologia para o estudo de Análise Combinatória. 2014. 151f. Dissertação (Mestrado em Educação Matemática) Instituto de Ciências Exatas. Universidade Federal de Juiz de Fora. Juiz de Fora.

GENTIL, Paulo. Bases científicas do treinamento de hipertrofia. Rio de Janeiro: SPRINT, 2005.

JACOBINI, Otávio Roberto; WODEWOTZKI, Maria Lúcia. Uma reflexão sobre a modelagem matemática no contexto da educação matemática crítica. Bolema, Rio Claro, v. 19, n. 25, p. 7188, 2006. 
MIRANDA, Marilia Gouveia de. O professor pesquisador e sua pretensão de resolver a relação entre a teoria e a prática na formação de professores. In ANDRÉ, Marli (Org.). O papel da pesquisa na formação e na prática dos professores. Campinas: Papirus, 2006, p. 129-143.

ROA, Rafael; BATANERO, Carmen, GODINO, Juan Díaz; CAÑIZARES, María Jésus. Estrategias en la resolución de problemas combinatorios por estudiantes con preparación matemática avanzada. Epsilon, v. 33, p. 433-446, 1997.

ROSA, Milton. A mixed-methods study to understand the perceptions of high school leaders about English Language Learners (ELL) students: the case of Mathematics. 2010. 583f. Dissertation (Doctorate of Education) - College of Education. California State University. Sacramento.

ROSA, Milton. Currículo e Matemática: algumas considerações na perspectiva etnomatemática. Plures Humaninades, Ribeirão Preto, v. 6, n. 6, p. 91-96, 2005.

ROSA, Milton. Desmitificando a análise combinatória. In: VI ENCONTRO NACIONAL DE EDUCAÇÃO MATEMÁTICA, 1998, São Leopoldo. Anais do VIENEM. São Leopoldo: SBEM, 1998, p. 323-324.

ROSA, Milton; OREY, Daniel Clark. A dimensão crítica da modelagem matemática: ensinando para a eficiência sociocrítica. Horizontes, Bragança Paulista, v. 25, n. 2, p. 197-206, 2007.

ROSA, Milton; OREY, Daniel Clark. A modelagem como um ambiente de aprendizagem para a conversão do conhecimento matemático. Bolema, Rio Claro, v. 26, n. 42A, p. 261-290, abr. 2012.

ROSA, Milton; OREY, Daniel Clark. Ethnomodelling as a creative insubordination approach in mathematics education. Journal of Mathematics and Culture, v. 10, n. 3, p. 111-134, 2016.

ROSA, Milton; OREY, Daniel Clark. Vinho e queijo: Etnomatemática e Modelagem! Bolema, Rio Claro, v.16, n. 20, p. 1-16, 2003.

SABO, Ricardo Dezso. Sabores docentes: a Análise Combinatória no Ensino Médio. 2010. $208 \mathrm{f}$. Dissertação (Mestrado em Educação Matemática) — Faculdade de Ciências Exatas e Tecnologia. Pontifícia Universidade Católica de São Paulo. São Paulo.

SANTOS, Rafael Henrique dos. Uma abordagem do ensino da Análise combinatória sob a ótica da Resolução de Problemas. 2011. 174f. Dissertação (Mestrado em Ensino de Ciências e Matemática) — Universidade Cruzeiro do Sul. São Paulo.

SILVA, Cintia da; KATO, Lilian Akemi; PAULO, Iramai Jorge Cabral de. A perspectiva sociocrítica da modelagem matemática e a aprendizagem significativa crítica: possíveis aproximações. Investigações em Ensino de Ciências, Porto Alegre, v. 17, n. 1, p. 109-123, jan./abr. 2012.

SKOVSMOSE, Ole. Cenários para investigação. Tradução de Jonei Cerqueira Barbosa. Bolema, Rio Claro, v. 13, n. 14, p. 66-91, 2000. 